\title{
The Effectiveness of an E-Learning Program on Nurse's Knowledge and Behavior for Caring of Patients with Thromboembolism: A Comparative Study
}

\author{
Bahrambeygi $\mathrm{F}^{1}$, Shojaeizadeh $\mathrm{D}^{2}$, Sadeghi $\mathrm{R}^{3}$, Nasiri $\mathrm{S}^{4}$ and Ghazanchaei $\mathrm{E}^{5 *}$ \\ ${ }^{1}$ Master student of health education and promotion at School of Public Health, Tehran University of Medical Sciences, Tehran, \\ Iran \\ ${ }^{2}$ Professor at School of Public Health, Tehran University of Medical Sciences, Tehran, Iran \\ ${ }^{3}$ Professor at School of Public Health, Tehran University of Medical Sciences, Tehran, Iran \\ ${ }^{4}$ Supervisor of Masih Daneshvari hospital, Tehran, Iran, \\ ${ }^{5}$ Lung Transplantation Research Center, National Research Institute of Tuberculosis and Lung Diseases (NRITLD), Shahid \\ Beheshti University of Medical Sciences, Tehran, Iran
}

*Corresponding author: Ghazanchaei E, Lung Transplantation Research Center, National Research Institute of Tuberculosis and Lung Diseases (NRITLD), Shahid Beheshti University of Medical Sciences, Tehran, Iran, Tel: 0989123382764, E-mail: el_gh2008@yahoo.com

Citation: Bahrambeygi F, Shojaeizadeh D, Sadeghi R, Nasiri S, Ghazanchaei E (2018) The Effectiveness of an E-Learning Program on Nurse's Knowledge and Behavior for Caring of Patients with Thromboembolism: A Comparative Study. J Nurs Healthcare Manag 1: 105

Article history: Received: 03 July 2018, Accepted: 29 August 2018, Published: 30 August 2018

\section{Abstract}

Background: Continuing education is an essential part of the nursing professionalization and it can be helpful for the nursing behavior development. It seems the area of continuing medical education programs is the most important areas that e-learning can play an important role. E-learning is an emerging approach to overcome some of the traditional education barriers and provides easy access and flexible learning. E-learning has been promoted as being more cost effective, convenient, and increasing opportunities for lifelong learning. To evaluate the effectiveness of an e-learning program to increase nurse's knowledge and behavior for caring of patients with VTE.

Method: 100 nurses were selected in a convenience method for e-learning and traditional education. All nurses had access to the internet and enough internet literacy. Each nurse in interventional group received 3 didactic files within the study period (4 weeks) that focused on VTE risk assessment, methods of VTE prophylaxis, VTE prophylaxis guidelines, Diagnosis, Pharmacological and Non-Pharmacological treatment and patient education. The nurses in the traditional group were taught by getting a traditional education, which was given by an expert lecturer.

Results: The findings of this study in regard to comparing knowledge level showed e-learning is not a superior learning method to traditional learning methods. The mean changes in behavior of the e-learning group was $3.16 \pm 1.49$ whereas that of the traditional group was $2.77 \pm 1.26$. Statistical analysis showed significant relationship between score change and e-learning education.

Conclusion: Using an e-learning program on CME programs is an effective learning method in addition to sitting in traditional course. We suggest that in later studies, the memorable effect of both methods be compared.

Keywords: E-learning; Nurse; Knowledge; Behavior; Education; Traditional

\section{Introduction}

Continuing medical education is the process by which health professionals keep updated to meet the needs of patients, the health service and their own professional development. It includes the continuous acquisition of new knowledge, skills and attitudes to enable competent practice [1]. Rapid advance in sciences forces healthcare professionals to always update their knowledge. Due to the fact that continuing medical education (CME) is widely applied. Choosing teaching method for CME is clearly related to developing technology, overpopulation, economic problems, geographical distribution, demands for more and better education, and people's willingness to self-motivation and self-learning. Continuing education based on needs assessment can improve learning outcomes [2].Continuing education is an essential part of the nursing professionalization and it can be helpful for the nursing practice development. Studies found that Web-based teaching seems to be as effective as traditional teaching in continuing education of nurses [3]. 
It seems that the area of continuing medical education programs is the most important areas that e-learning can play an important role. Reasons for this can be seen as follows:

1-The society who needs CME, is the wide geographical spread.

2-They don't have the same time to learn new objects.

3-In terms of the diversity of geographical and occupational status, educational needs can be different.

4-Learning interests may be different [4].

Nursing has adopted e-learning as an appropriate alternative to traditional learning environments [5]. Because of several factors such as family involvement, shift work exhaustion, low motivation, lack of replacement staff and interfere of continuing education programs with their working, e-learning is considered inexpensive and effective solution [6]. The e-learning program is appropriate for nurses to resolve the problems resulting from nurses' inability to be present at traditional courses because of shift schedules. This comparative study has offered comparing the e-learning and traditional method for developing nurse's knowledge and behavior in caring patients with venous thromboembolism.

E-learning is an emerging approach to overcome some of the traditional education barriers and provides easy access and flexible learning. It is widely accepted that advances in information technology and new developments in learning science provide opportunities to create well-designed, learner-centered, interactive, affordable, efficient, flexible e-learning environments [7]. E -learning, as a positive reaction by universities to the challenge introduced by IT, is characterized by: (1) separation in time and/ or space between the teacher and students, among the students themselves, and between the students and educational resources; (2) interaction between the teacher and students, among the students, and between the students and educational resources by means of one or more media, especially through the Internet; and (3) a process of teaching and learning not limited to the immediate time and/or place [8].

E-learning has been promoted as being more cost effective, convenient, and increasing opportunities for lifelong learning. It has demonstrated several advantages over traditional learning, especially in allowing "learning anytime and anywhere." Students have access to online course materials independent of time and place. It also allows students to reflect on the learning materials and their responses, and permits them to work at their own pace, regardless of race, sex and disability or appearance [9]. E-learning also provides students the opportunity to preview and practice, and students have high satisfaction with online learning [10]. The multisession use of the online resources may indicate an advantage of sequential reinforcement with e-learning education [11].

While E-learning has advantages, it is equally important to note that there are disadvantages. These might include little or no "in-person" contact with the faculty member, feelings of isolations, a difficult learning curve in how to navigate within the system, problems with the technology, the need for the student to be actively involved in learning, and increased lead-time required for feedback regarding assignments [12].

A review by Cook et al. has demonstrated the use of e-learning or 'internet-based education' is associated with a positive effect on the knowledge, skills, and behavior of healthcare professionals, as well as on patient outcomes. The recent research conducted by recommended online learning had many benefits for busy professionals, in particular from the ease of access and use [13].

Many studies have appeared in the last decade which show the impact of information and communication technologies (ICT) on nursing education. Moule, et al. demonstrated nurses have positive attitudes to on-line learning and suggested online learning had many benefits for busy professionals [14]. Morente, et al. discovered the suitability of the e-learning as an effective instrument for training on assessment of and treatment for pressure ulcers and its potential impact on clinical decision-making for nurses [15]. Khatoni, et al. compared the effect of web-based education and traditional education on nurse's knowledge about Bird Flu in continuing education [16]. This study found that web-based teaching is as effective as traditional teaching in continuing education of nurses. A review by Lahti, et al. compared the impact of e-learning with traditional education in the acquisition of knowledge, skills and satisfaction among nurses [17]. This review showed that there is no difference between e-learning or traditional learning. Lee, et al. suggested that using an e-learning program for pediatric medication management is an effective learning method, supplementary to sitting in a standard lecture course [5]. This e-learning program is suitable for pediatric nursing courses with limited class hours, and can help students deal with unfamiliar situations.

Al-Hameed, et al. recommended a CME educational program to improve VTE prophylaxis utilization [18]. Their research reveal that appropriate VTE prophylaxis rate for patients who developed VTE during hospitalization increased significantly after a hospital-wide CME program and the proportion of hospital deaths associated with VTE tended to decrease after the CME program. Similar studies from the more general field of biomedicine have also shown the advantages of applying e-learning systems into professional education programs $[5,15,19]$.

Compared the knowledge and skill of physicians before and after contribution in traditional and electronic continuous medical education, showed that the e-learning was an effective approach to create deep and lasting learning in the participant of continuous medical education [20]. As a more recent example, in the use of an on-line e-learning system for nurses in delirium care showed an e-learning course on delirium did have a significant effect on the nursing staff's delirium care for older patients. This study found a significant increase in the knowledge of delirium after nurses completed the e-learning course [21]. 
In addition to all the above mentioned cases, it is difficult to arouse the motivation and participation of nurses in their own education and promoting their abilities. The five most important factors that prevented nurses from participating in CME were work commitments, domestic responsibilities, time constraints, scheduling of CME activities and cost of courses which are consistent with those found in previous studies [22]. E-learning is a powerful tool that is able to overcome these obstacles and, furthermore, it is making the nurses active as well as a responsible part of their own education.

The aim of this study was to determine and compare the knowledge and behavior of Masih Daneshvari hospital nurses, both before and after participation in e-learning and traditional education on thromboembolism.

\section{Materials and Methods}

This was a Comparative study that was conducted at National Research Institute of Tuberculosis and Lung Disease, Masih Daneshvari Hospital, Shaheed Beheshti Medical University, a hospital in Tehran, Iran. The intervention we studied was an e-learning and traditional course on thromboembolism geared towards hospital nursing staff. By using a pilot study and mean comparison formula, the sample size was estimated to be 48 subjects per group. Considering the $10 \%$ dropout rate, 53 nurses were enrolled in each group. The inclusion criteria were as follows: nurses with a bachelor's degree or higher which had not ever participate in e-Learning programs and Continuing Education Program of venous thromboembolism, willingness to participate in the study, access to the internet, enough internet literacy. The exclusion criteria were as follows: lack of participation in the educational sessions (for traditional group), failure to receive e-mail messages (for e-learning group). Randomized available sampling was used. At each stage of the study, there was a right to withdraw from the study for samples.

The wards of the hospital were located in four separate buildings .53 nurses from the northern wards of the hospital were selected randomly for traditional education and 53 nurses from southern parts of the hospital were randomly selected for e-Learning. At the beginning of the study, each group consisted of 53 nurses. However, during the study three nurses from the traditional group and three nurses from the e-learning group were excluded due to lack of participation in the educational sessions and absence from the post test.

Questionnaire (Pretest/posttest) and checklist were used to evaluate the impact of the intervention. A researcher-made questionnaire was designed in three sections. In the first part, demographic and job information in 8 questions, in the second part, access and use of the Internet and e-mail and participation in Continuing Education Program in 12 questions. The third part, the awareness questionnaire consisted of 20 questions which according to the scientific resources available in relation to venous thromboembolism were arranged. Knowledge related to VTE risk assessment, methods of VTE prophylaxis, VTE prophylaxis guidelines, diagnosis, pharmacological and non-pharmacological treatment and patient education was developed for the study. Each correct answer was worth 1 points. Content validity method was used to determine the validity of the tools. Books, journals and articles were studied and questionnaires were adjusted using the opinions of supervisors, the statistics and the consultant. In order to determine content validity, the questionnaire was sent to ten cardiologist and pulmonary specialist and their comments were used. The Test-retest method was used to the reliability of the questions. Therefore, 20 nurses with the same characteristics and conditions as the units under study, completed the questionnaire. Two weeks later, the questionnaire was re-submitted to the respondents. The correlation coefficient was calculated. The Content Validity Index of the scale was over 0.80 , representative acceptable content validity. Correlation coefficient value for the scale was 0.838 , indicating suitable reliability.

A checklist contains of 14 items, including behavior related to VTE risk assessment, methods of VTE prophylaxis, VTE prophylaxis guidelines, diagnosis, pharmacological and non-pharmacological treatment and patient education was established for the study. Each correct behavior was worth 1 points.

Educational content that was identical for both groups, was prepared through the study of reference books and guidelines for the American Heart Association. In order to determine validity, it was sent to ten cardiologist and pulmonary specialist and their comments were used. The educational content focused on VTE risk assessment, methods of VTE prophylaxis, VTE prophylaxis guidelines, diagnosis, pharmacological and non-pharmacological treatment and patient education.

For E-learning group, educational content was developed as text files and color images and for the traditional group, similar educational content was developed using PowerPoint program and the same images.

The intervention proceeded by holding a meeting with staff in e-learning group to inform them of the objectives of the research and ensuring that they have the ability to use the Internet and email. The researcher was taught to use the e-mail to all the nurses and their e-mail addresses were given to the researcher with satisfaction. The researcher provided her e-mail and telephone number to all of them. The possibility of telephone and e-mail calls for questioning about educational content was provided for all the nurses in e-learning group.

Before starting the educational intervention, a written pretest was given to the nurses for evaluating their background knowledge on thromboembolism. Each nurse in interventional group received 3 didactic files within the study period (4 weeks). With the aim of remind nurses to study the email messages, they received regular text messages contained an overview of the key messages related to the prevention and treatment. A day after accomplishment the intervention, a written posttest was given to the nurses. 
On the other hand, the nurses in the control group were taught by getting a traditional education, which was given by training supervisor of Masih Daneshvari hospital, who is an instructor of continuing education of Shahid Beheshti University. They met in a classroom equipped with standard audiovisual media. Before beginning the class, they completed the same pre-test as the experimental group. Thereafter, an instructor taught the nurses educational content was developed using PowerPoint program. The traditional class, had a duration of 4 hours. Upon completion of the class, the nurses answered the posttest which was the same as posttest in the experimental group.

In addition, we have designed a checklist to evaluate nurse's behavior before and after the intervention which applied in both groups. Before starting the educational intervention, the nurse's behavior towards the VTE were under the insensible observing to evaluate their background practice on VTE. One month after intervention, their behavior were evaluated by the use of same checklist. To encourage accomplishment, nurses who achieved a score of more than 15 for knowledge and more than 10 for behavior, received 8 continuing education credits.

\section{Data analysis}

All statistical analyses were accomplished using IBM SPSS, version 19.0. Statistical significance for all analyses was set as $\alpha=$ 0.05. Shapiro-wilk was used to analyze the data distribution. Due to the lack of normal changes in both knowledge and behavior variables, non-parametric Mann-Whitney and Kruskal Valis were used to measure the difference between samples.

\section{Results}

Characteristics of participantsA total of 100 people participated in the CME program. As can be seen in Table 1, most participants were female nurses $(94 ; 94 \%)$. Almost half of nurses aged $30-40$ years $(51 ; 51 \%)$ and slightly more than half of them were married (52; 52\%). Most participants had earned a bachelor's in nursing $(94 ; 94 \%)$ and less than half of the participants were working in shifts day and night $(41 ; 41 \%)$. The mean and standard deviation number of working years as a nurse was 10/96 $\pm 6 / 03$ years. Differences between groups were tested using the Chi-square test, e-learning group and traditional group was the same at all the variables (Table 1).

\begin{tabular}{|c|c|c|c|c|c|c|c|c|}
\hline & \multicolumn{4}{|c|}{ E- LEARNING } & \multicolumn{4}{|c|}{ TRADITIONAL } \\
\hline & \multicolumn{2}{|c|}{ Knowledge } & \multicolumn{2}{|c|}{ Behavior } & \multicolumn{2}{|c|}{ Knowledge } & \multicolumn{2}{|c|}{ Behavior } \\
\hline & Before & After & Before & After & Before & After & Before & After \\
\hline \multicolumn{9}{|l|}{ GENDER } \\
\hline Female & $10.89 \pm 2.53$ & $16.70 \pm 1.98$ & $3.64 \pm 0.81$ & $6.89 \pm 1.57$ & $10.57 \pm 2.09$ & $14.91 \pm 1.53$ & $3.54 \pm 0.62$ & $5.91 \pm 1.11$ \\
\hline Male & $12.67 \pm 2.30$ & $15.33 \pm 1.15$ & $3.67 \pm 1.15$ & $6.00 \pm 1.73$ & $9.75 \pm 3.59$ & $15.00 \pm 1.41$ & $3.00 \pm 0.81$ & $5.75 \pm 1.50$ \\
\hline $\mathrm{p}$-value & \multicolumn{2}{|c|}{$\mathrm{p}$-value $=0.04, \mathrm{z}=-2.04$} & \multicolumn{2}{|c|}{$\mathrm{p}$-value $=0.30, \mathrm{z}=-1.03$} & \multicolumn{2}{|c|}{$\mathrm{p}$-value $=0.471, \mathrm{z}=-0.721$} & \multicolumn{2}{|c|}{$\mathrm{p}$-value $=0.485, \mathrm{z}=-0.698$} \\
\hline \multicolumn{9}{|l|}{ MARITAL STATUS } \\
\hline Single & $10.70 \pm 2.36$ & $16.78 \pm 2.19$ & $3.57 \pm 0.94$ & $7.00 \pm 1.70$ & $10.56 \pm 2.12$ & $15.32 \pm 1.06$ & $3.44 \pm 0.71$ & $5.96 \pm 1.17$ \\
\hline Married & $11.26 \pm 2.69$ & $16.48 \pm 1.78$ & $3.70 \pm 0.72$ & $6.70 \pm 1.48$ & $10.44 \pm 2.32$ & $14.52 \pm 1.78$ & $3.56 \pm 0.58$ & $5.84 \pm 1.10$ \\
\hline p-value & \multicolumn{2}{|c|}{$\mathrm{p}$-value $=0.08, \mathrm{z}=-1.72$} & \multicolumn{2}{|c|}{$p$-value $=0.27, z=-1.09$} & \multicolumn{2}{|c|}{$\mathrm{p}$-value $=0.045, \mathrm{z}=-2.00$} & \multicolumn{2}{|c|}{$\mathrm{p}$-value $=0.269, \mathrm{z}=-1.10$} \\
\hline \multicolumn{9}{|l|}{ EDUCATIONAL LEVEL } \\
\hline Bachelor & $10.94 \pm 2.59$ & $16.60 \pm 2.01$ & $3.62 \pm 0.84$ & $6.77 \pm 1.56$ & $10.49 \pm 2.21$ & $14.93 \pm 1.46$ & $3.47 \pm 0.65$ & $5.87 \pm 1.15$ \\
\hline Master & $12.00 \pm 1.00$ & $17.00 \pm 1.00$ & $4.00 \pm 0.00$ & $8.00 \pm 1.73$ & $10.67 \pm 2.51$ & $14.66 \pm 2.51$ & $4.00 \pm 0.00$ & $6.43 \pm 0.57$ \\
\hline $\mathrm{p}$-value & \multicolumn{2}{|c|}{$\mathrm{p}$-value $=0.82$} & \multicolumn{2}{|c|}{$\mathrm{p}$-value $=0.82$} & \multicolumn{2}{|c|}{$\mathrm{p}$-value $=0.523$} & \multicolumn{2}{|c|}{$\mathrm{p}$-value $=0.879$} \\
\hline \multicolumn{9}{|l|}{ SHIFTS } \\
\hline Morning & $7.15 \pm 1.21$ & $3.77 \pm 0.72$ & $17.00 \pm 1.73$ & $10.77 \pm 2.61$ & $7.15 \pm 1.21$ & $3.77 \pm 0.72$ & $17.00 \pm 1.73$ & $10.77 \pm 2.61$ \\
\hline Morning and evening & $10.77 \pm 2.61$ & $17.00 \pm 1.73$ & $3.77 \pm 0.72$ & $7.15 \pm 1.21$ & $10.00 \pm 2.34$ & $14.55 \pm 1.50$ & $3.78 \pm 0.44$ & $6.22 \pm 0.97$ \\
\hline Evening and night & $10.95 \pm 2.70$ & $16.35 \pm 1.98$ & $3.65 \pm 0.98$ & $6.65 \pm 1.66$ & $10.95 \pm 2.16$ & $15.40 \pm 1.42$ & $3.55 \pm 0.68$ & $6.05 \pm 1.09$ \\
\hline Circulate & $11.71 \pm 2.13$ & $16.43 \pm 2.22$ & $3.71 \pm 0.75$ & $6.86 \pm 1.77$ & $9.33 \pm 2.58$ & $14.50 \pm 1.04$ & $3.17 \pm 0.75$ & $5.67 \pm 1.63$ \\
\hline $\mathrm{p}$-value & \multicolumn{2}{|c|}{$\mathrm{p}$-value $=0.68$} & \multicolumn{2}{|c|}{$\mathrm{p}$-value $=0.86$} & \multicolumn{2}{|c|}{$\mathrm{p}$-value $=0.68$} & \multicolumn{2}{|c|}{$\mathrm{p}$-value $=0.86$} \\
\hline \multicolumn{9}{|c|}{$\begin{array}{l}\text { INTRESTED IN CONTINUING } \\
\text { EDUCATION PROGRAM }\end{array}$} \\
\hline NO & $8 \pm 4.24$ & $14.50 \pm 0.70$ & $3.00 \pm 1.41$ & $5.50 \pm 0.70$ & $9.67 \pm 4.16$ & $15.00 \pm 1.73$ & $3.00 \pm 1.00$ & $5.33 \pm 1.52$ \\
\hline Low & $12.00 \pm 2.00$ & $18.00 \pm 2.00$ & $3.67 \pm 1.15$ & $8.33 \pm 1.15$ & $10.60 \pm 1.81$ & $15.40 \pm 1.14$ & $3.40 \pm 0.54$ & $5.80 \pm 0.83$ \\
\hline Medium & $10.72 \pm 2.67$ & $16.84 \pm 1.88$ & $3.63 \pm 0.87$ & $6.97 \pm 1.53$ & $10.53 \pm 2.20$ & $14.94 \pm 1.59$ & $3.53 \pm 0.66$ & $6.06 \pm 1.17$ \\
\hline High & $11.92 \pm 1.65$ & $16.08 \pm 2.06$ & $3.33 \pm 0.59$ & $6.38 \pm 1.66$ & $10.63 \pm 1.99$ & $14.50 \pm 1.41$ & $3.63 \pm 0.51$ & $5.50 \pm 0.92$ \\
\hline $\mathrm{p}$-value & \multicolumn{2}{|c|}{$\mathrm{p}$-value $=0.15$} & \multicolumn{2}{|c|}{$\mathrm{p}$-value $=0.19$} & \multicolumn{2}{|c|}{$\mathrm{p}$-value $=0.516$} & \multicolumn{2}{|c|}{$\mathrm{p}$-value $=0.248$} \\
\hline
\end{tabular}

Table 1: Descriptive statistics of the participants, characteristic variables for both groups Changes in knowledge and behavior 
The results indicate, prior to the e-learning program, the nurses possessed limited knowledge towards venous thromboembolism $(\mathrm{M}=11, \mathrm{SD}=2.53)$ (Knowledge score was calculated of 20). After completing the program, the average knowledge score of the e-learning group increased from $11 \pm 2.53$ in the pretest to $16.62 \pm 1.96$ in the posttest. Whereas that of the traditional group enhanced from $10.50 \pm 2.20$ in the pretest to $14.92 \pm 1.50$ in the posttest. The mean changes in knowledge of the e-learning group was $5.62 \pm 2.85$ while that of the traditional group was $4.42 \pm 1.31$ (Table 2 ).

\begin{tabular}{|c|c|c|c|c|}
\hline \multirow{2}{*}{} & \multicolumn{2}{|c|}{ E- LEARNING } & \multicolumn{2}{c|}{ TRADITIONAL } \\
\cline { 2 - 5 } & Before & After & Before & After \\
\hline Knowledge & $11 \pm 2.53$ & $16.62 \pm 1.96$ & $10.50 \pm 2.20$ & $14.92 \pm 1.50$ \\
\hline Behavior & $3.64 \pm 0.82$ & $6.84 \pm 1.58$ & $3.50 \pm 0.64$ & $5.90 \pm 1.12$ \\
\hline
\end{tabular}

Table 2: Changes in knowledge and behavior

Although at first glance it seems that the mean changes in knowledge of the e-learning group is higher, statistical analysis did not show any significant relationship between score change and type of education (Figure 1).

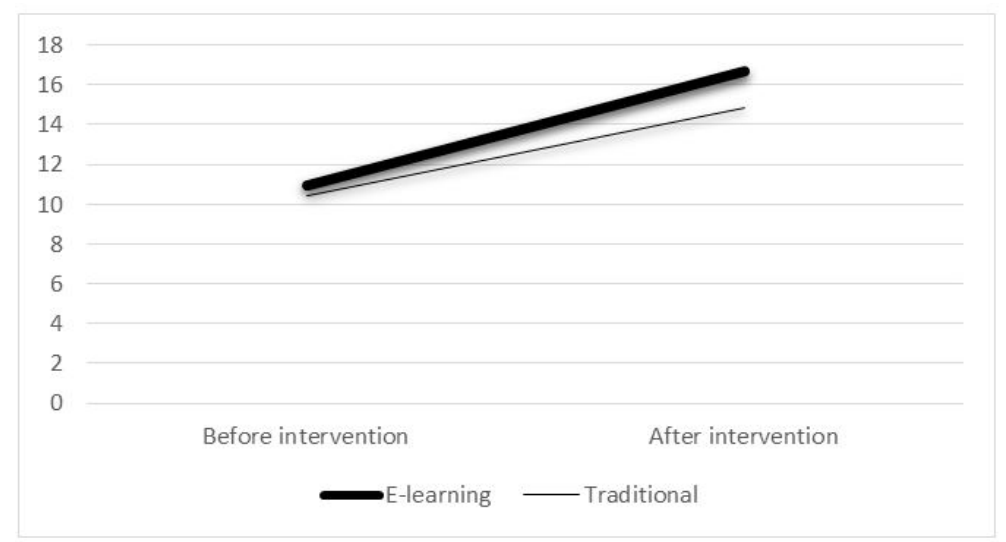

Figure 1: Changes in nurses' knowledge for both groups

\section{Changes in behavior}

The result demonstrate the mean behavior score of the e-learning group improved from $3.64 \pm 0.82$ before the e-learning program to $6.84 \pm 1.58$ after the program, whilst that of the traditional group advanced from $3.50 \pm 0.64$ before the traditional education to $5.90 \pm 1.12$ after the program. (Behavior score was calculated of 20). The mean changes in behavior of the e-learning group was $3.16 \pm 1.49$ whereas that of the traditional group was $2.77 \pm 1.26$. Statistical analysis showed significant relationship between score change and type of education. Changes in the behavior of e-Learning is more than the rate of change in the traditional education (Figure 2).

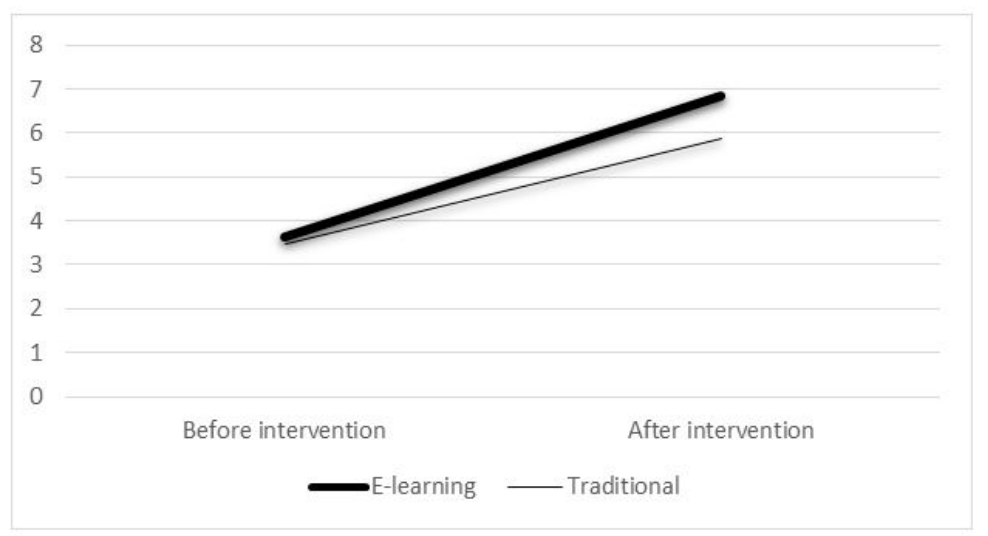

Figure 2: Changes in nurses 'behavior in both groups

\section{Discussion}

This intervention aimed to investigate the impact of e-learning on knowledge and behavior among nurses comparing to traditional education methods. The findings of this study in regard to comparing knowledge level showed e-learning is not a superior learning method to traditional learning methods. However, the pre-test in compared with the post-test in both groups exhibited an increase in the level of knowledge, there was not found any significant relationship between the type of educational methods and changes in the knowledge level. In addition, we surprisingly have found e-learning is more effective in improving learners' behavior than traditional methods. 
This finding mirrors that of Hugenholtz, et al., who through randomized controlled trial that was conducted in December 2006, found e-learning is just as effective in enhancing knowledge as lecture-based learning [23]. The finding also is in line with recent review of Lahti, et al., who indicated there was no statistical difference between groups in e-learning and traditional learning relating to nurses or student nurses knowledge [17]. Many previous studies have acknowledged that e-learning programs are flexible in time, location and content $[4,24,25]$. The results of this study are consistent with Lee, et al. who through intervention study with 349 undergraduate nursing students, found the e-learning group were greater improvements in pediatric medication management and the students learned how to integrate medication knowledge and skills [5].

On the other hand to facilitate working nurse's abilities to participate in continuing education programs, hospitals are increasingly teaming with universities to bring educational opportunities on site and offer online courses. Due to the above, while e-learning effectiveness, cost-effective is [26].

Several factors could have contributed to improving learner's behavior in e-learning method. First, online CME learners completed the learning activity over several sessions, while traditional learners often have a single. Second, learners have a possibility to visit their e-mail several times and repeated visits to the e-mail may have provided additional reinforcement of learning. Third, performance may have been improved because online CME learners can manage their learning. They can use other sources in web for expanding their information, assigning time to each educational section as desired and enabling to choose the place and time to educate themselves. While some of the nurses who receiving traditional teaching methods, participated in their training class after night shift. In this sense, there is an obvious contrast between e-learning and traditional groups $[4,17,25]$.

Furthermore, Online CME learners also had received regular text messages contained an overview of the key messages. The messages and the multisession use of the online resources may indicate an advantage of sequential reinforcement with e-learning education [11].

\section{Limitations}

Limitations of this study need to be considered. First, since that was the first e-learning course in this hospital and the technology infrastructure did not enough progressed, nurses had some problems for using the internet (They had the adequate ability to use the Internet There were very few problems in the infrastructure). Second, the short time period ( 1 months) for follow-up measurement was not enough to achieve certain results. The measurement of skill or performance was limited as the time was short.

\section{Conclusion}

This intervention study has offered comparing the e-learning and traditional method for developing nurse's knowledge and behavior in caring patients with VTE. Using an e-learning program on CME programs is an effective learning method in addition to sitting in traditional course. The e-learning program is appropriate for nurses to resolve the problems resulting from nurses' inability to be present at traditional courses because of shift schedules. E-learning is a powerful tool that is able to overcome traditional education obstacles and, furthermore, it is making the nurses active as well as a responsible part of their own education. whereas e-learning has been developed as being more cost effective, accessible, and increasing opportunities for lifelong learning, it can be one of the best education tools for nurses Considering the main goal of education is changing the behavior, the results confirm that e-learning is an appropriate instrumentation to achieving this target. It is recommended that studies be conducted to compare retention in these teaching methods.

\section{References}

1. Peck C, McCall M, McLaren B, Rotem T (2000) Continuing medical education and continuing professional development: international comparisons. BMJ 320: 432-5.

2. Alinier G, Hunt B, Gordon R, Harwood C (2006) Effectiveness of intermediate-fidelity simulation training technology in undergraduate nursing education. J Adv Nurs 54: 359-69.

3. Griscti O, Jacono J (2006) Effectiveness of continuing education programs in nursing. J Adv Nurs 55: 449-56.

4. Zanjani Nk (2012) Structured Analysis of Requirements and Challenges of ELearning and Proposing a Practical Model for Successful Implementation of ECourses in Medical Sciences. Iranian J Med Edu 11: 995-1009.

5. Lee T-Y, Lin F-Y (2013) The effectiveness of an e-learning program on pediatric medication safety for undergraduate students: A pretest-post-test intervention study. Nurse Educ Today 33: 378-83.

6. Gooshi M, Sirati M, Khaghanizade M (2014) Utilization Conditions of Virtual Education at Continuing Education for nurses: A review. Int Med Rev 1.

7. Khan BH (2005) Managing e-learning: Design, delivery, implementation, and evaluation: IGI Global; 2005.

8. Oh CH (2003) Information communication technology and the new university: A view on eLearning. The Annals of the American Academy of Political and Social Science 585: 134-53.

9. Richardson J, Swan K (2003) Examing social presence in online courses in relation to students' perceived learning and satisfaction.

10. Chumley-Jones HS, Dobbie A, Alford CL (2002) Web-based learning: Sound educational method or hype? A review of the evaluation literature. Acad Med 77: S86-93.

11. Curran VR, Fleet LJ, Kirby F (2010) A comparative evaluation of the effect of internet-based CME delivery format on satisfaction, knowledge and confidence. BMC Med Educ 10: 10.

12. Al-Lozi M, Alrowwad A (2016) A Review of Literature on E-Learning Systems in Higher Education. Int J Business Manag Economic Res 7: 754-62. 
13. Hajli M, Bugshan H, Lin X, Featherman M (2013) From e-learning to social learning-a health care study. Euro J Training Develop 37: 851-63.

14. Moule P, Pollard K, Armoogum J, Messer S (2015) Virtual patients: Development in cancer nursing education. Nurse Educ Today 35: 875-80.

15. Morente L, Morales-Asencio JM, Veredas FJ (2014) Effectiveness of an e-learning tool for education on pressure ulcer evaluation. J Clin Nurs 23: 2043-52.

16. Khatoni A, Dehghan Nayery N, Ahmady F, Haghani H (2011) The effect of web-based and traditional instructions on nurses' knowledge about AIDS. Iranian J Med Edu 11: 140-8.

17. Lahti M, Hätönen H, Välimäki M (2014) Impact of e-learning on nurses' and student nurses knowledge, skills, and satisfaction: a systematic review and meta-analysis. Int J Nurs Stud 51: 136-49.

18. Al-Hameed F, Al-Dorzi HM, Aboelnazer E (2014) The effect of a continuing medical education program on Venous thromboembolism prophylaxis utilization and mortality in a tertiary-care hospital. Thromb J 12: 9.

19. Baghaie R, Rasouli D, Rahmani A, Mohammadpour Y, Jafarizade H (2012) Effect of web-based education on cardiac disrhythmia learning in nursing student of Urmia University of Medical Sciences. Iranian J Med Edu 12: 240-8.

20. Mohammadimehm M, Sanaiey NZ, Rahim M (2012) The comparison study of Knowledge and skill of physicians before and after contribution in traditional and electronic continuous Medical Education Diabetic course. Media 3: 21-30.

21. van de Steeg L, IJkema R, Langelaan M, Wagner C (2014) Can an e-learning course improve nursing care for older people at risk of delirium? J Bio Med 14: 1-8.

22. Chong MC, Sellick K, Francis K, Abdullah KL (2011) What influences Malaysian nurses to participate in continuing professional education activities? Asian Nurs Res (Korean Soc Nurs Sci) 5: 38-47.

23. Hugenholtz NI, De Croon EM, Smits PB, Van Dijk FJ, Nieuwenhuijsen K (2008) Effectiveness of e-learning in continuing medical education for occupational physicians. Occup Med 58: 370-2.

24. Liu W-I, Rong JR, Liu CY (2014) Using Evidence Integrated e-Learning to Enhance the Case Management Continuing Education for Taiwanese Psychiatric Nurses.

25. Zolfaghari M, Mehrdad N, Parsa Yekta Z, Salmani Barugh N, Bahrani N (2007) The effect of lecture and e-learning methods on learning mother and child health course in nursing students. Iranian J Med Edu 7: 31-9.

26. Horiuchi S, Yaju Y, Koyo M, Sakyo Y, Nakayama K (2009) Evaluation of a web-based graduate continuing nursing education program in Japan: a randomized controlled trial. Nurse Edu Today 29: 140-9. 